\title{
Entre imaginários e representações: o ensino da História e Cultura Indígena na instituição escolar
}

\author{
Among imaginaries and representations: Teaching History and \\ Indigenous Culture in the school institution
}

Entre imaginarios y representaciones: Historia de la enseñanza y Cultura Indígena en la institución escolar

Recebido em 14-07-2020

Modificado em 09-10-2020

Aceito para publicação em 14-03-2021

doi https://doi.org/10.47456/simbitica.v8i2.36382

\section{Joselaine Dias de Lima Silva}

ORCID:0000-0003-1633-0971

Mestra em Integração Contemporânea da América Latina pela Universidade Federal da Integração Latinoamericana, Brasil. Doutoranda em História pelo PPGH da Universidade Federal da Grande Dourados, Brasil. Email: joselainesilva_9@hotmail.com

\section{Resumo}

O objetivo do ensaio é refletir a respeito do imaginário social na sociedade brasileira a cerca das populações indígenas. Investigar como esse imaginário é representado no contexto escolar e em alguns materiais didáticos observando a Lei 11.645/2008, promulgada no intuito de corresponder aos anseios e exigências das centenas de etnias indígenas existentes no Brasil. A análise procura, mediante pesquisa teórica, pensar a partir da teoria decolonial, a necessidade de relacionar as histórias e culturas indígenas nos currículos do contexto educacional. Nessa direção, o presente ensaio propõe avaliar a influência dos livros didáticos no desenvolvimento da consciência histórica dos alunos e da sociedade envolvente.

Palavras-chave: Lei 11.645/2008; teoria decolonial; questão indígena; consciência histórica. 


\section{Introdução}

O presente ensaio ampara-se em contribuições teóricas articulando um diálogo mais profícuo com o objeto da pesquisa trazendo elementos que possam interessar e contribuir com a questão do ensino da história e cultura indígena na educação básica. As discussões aqui apresentadas resultam de estudos que abordam a diversidade cultural e a descolonização dos currículos, a partir da Lei 11.645/2008, com foco na educação básica.

Retomaremos, nesse primeiro momento a interrogação deixada por Marc Bloch (2001) em sua obra Apologia da História ou o ofício do historiador. Afinal, para que serve a História? Bloch apresenta questões pertinentes a respeito do ofício do historiador e reconhece que a História precisa sempre dialogar com outras disciplinas. O autor também acredita que a função do historiador é apontar a necessidade de entender o mundo ao seu redor e buscar meios de se comunicar com ele, um exercício que vai além da compreensão das fontes e arquivos. Bloch (2001) afirma que o indivíduo e a sociedade são polos de interesse da História, portanto, concentra-se no social e no humano e em sua dimensão com o tempo. A História ressalta a necessidade de percebermos as diferenças culturais e por meio de seu estudo, auxiliar no entendimento do outro, e das culturas diversas.

A função do historiador consiste em apresentar elementos que contribuam para a formação da consciência histórica, uma vez que o intuito da história é estudar e analisar o que realmente aconteceu e acontece dentro da sociedade. Para Chartier (2009), as representações não são simples imagens, verdadeiras ou falsas de uma realidade que lhe seria externa, elas possuem uma energia própria que leva a crer que o mundo ou o passado é, efetivamente, o que dizem que é. Nesse sentido, produzem brechas que mobilizam sociedades e as incorporam nos indivíduos. Nessa linha de pensamento, analisamos as narrativas imagéticas construídas sobre os grupos indígenas, observando a relação entre ensino, representação e consciência histórica, uma vez que, o discurso hegemônico por séculos não deu ouvidos às vozes subalternizadas. Como argumenta Cunha (1992), os povos colonizados foram vistos, sem lugar e sem história, fadados ao esquecimento.

Assim, para melhor tratarmos o assunto, assumimos a concepção de Michel de Certeau (1982) em sua obra A escrita da História, na qual o autor argumenta que a História seria ao mesmo tempo uma disciplina, uma prática e uma escrita. Neste sentido, pensar a História como uma disciplina implica conceber que ela faz parte de um lugar social e sua escrita se organiza em função de uma instituição, sendo pelo meio do interesse institucional que a História se constitui como matéria curricular. 
Para uma análise mais voltada à temática do ensino da história e cultura indígena, nos atemos a Lei 11.645/2008 que oportuniza em todo o currículo da educação básica as disciplinas de História, Artes e Língua Portuguesa romperem com uma narrativa histórica de tradição eurocêntrica, nas quais as narrativas nacionais foram forjadas a favor da manutenção de poderes e privilégios dos grupos e classes hegemônicas. Esta lei representa um marco fundamental na construção de um currículo que prima pela diversidade trazendo ao debate educacional, sujeitos historicamente silenciados.

Dessa forma, a Lei 11.645/2008 se estabelece como um marco republicano de cumprimento da Constituição de 1988 e a possibilidade de aprofundamento da democracia, uma vez que diversas vozes e sujeitos foram chamados para participar da construção desse capítulo da sociedade brasileira (Fanelli, 2018). Em relação ao assunto, é necessário ressaltar o tempo histórico no qual este ensaio está sendo produzido, pois têm ocorrido turbulentos ataques aos direitos indígenas e vivenciamos um retrocesso em relação aos direitos que foram conquistados através da Constituição Federal de 1988. Para Fanelli (2018) é notório que a implantação da Lei ocorreu na ocasião em que suportes foram constituídos para incluir um currículo escolar que reconhecesse a diversidade cultural.

$\mathrm{Na}$ sequência do ensaio discutiremos o poder do imaginário sobre o indígena na sociedade brasileira, em especial no tratamento da questão a partir dos livros didáticos de História utilizados nas escolas estaduais do Estado de Mato Grosso do Sul. Também abordaremos o ensino de história e cultura indígena no contexto escolar, abarcando o processo de consciência histórica, pensando a proposta decolonial como princípio do diálogo e reconhecimento pluriétnico.

\section{O poder do imaginário sobre o indígena na sociedade nacional}

Com vistas à dominação, no período colonial, por parte dos invasores e setores a estes relacionados como clero, por exemplo, inicia-se a construção de uma imagem histórica dos diversos povos indígenas no Brasil marcada por estereótipos e estigmas. A colonização passou por fases relacionadas à exploração territorial, produção e comercialização de matérias e artefatos. Como exemplo, Albert Dürer, citado por Todorov, desde 1520 admira as obras dos artesãos indígenas, enviadas por Cortez à corte real. O mesmo Dürer, inclusive, continuaria a forjar uma imagem dos indígenas ao desenhar e produzir imagens fiéis ao espírito europeu. 
Tzvetan Todorov ao escrever sobre o espanhol e cristão Hernán Cortez, nos oferece um vislumbre desses imaginários que perpassam os poderes e revestem o interesse do invasor pela civilização asteca: um encontro que o instiga, ao mesmo tempo que o provoca um completo estranhamento (Todorov, 2003:4).

Um outro exemplo, o estranhamento dos portugueses ao se depararem com a natureza dos trópicos. Os mananciais, o clima, a densa vegetação que encobria as paisagens junto ao litoral banhado de altas temperaturas, o impacto da diferença em relação aos campos europeus deve ter sido de imensa repercussão. Existia também uma multiplicidade de povos, línguas, culturas e modos de viver que não passavam pelo crivo do imaginário europeu.

Nesse sentido, nossa reflexão dialoga com a opinião da relatora do Parecer 3/2004 ${ }^{1}$ da Comissão Nacional de Educação, quando ela defende que não é mais possível ignorar que naqueles territórios viviam pessoas em sociedades que desenvolviam culturas.

"A ideia distorcida de que os portugueses descobriram o Brasil repercute até hoje na mentalidade de muitos que pensam que o mundo, as pessoas, os costumes e as ideias passam a existir quando deles tomam conhecimento" afirmou Petronilha Beatriz Gonçalves ${ }^{2}$.

Entendemos o conceito de imaginário a partir dos escritos de Walter Mignolo (2005), que dialogando com o escritor martinicano Édouard Glissant (1997), vai dizer que o imaginário não tem relação com uma imagem mental, tampouco o sentido técnico do discurso analítico, no qual o imaginário forma uma estrutura de diferenciação com o real, o simbólico, mas que assume um sentido geopolítico e o emprego na fundação e formação do imaginário do sistema-mundo moderno colonial (Mignolo, 2005:35).

Sobre o assunto, o historiador e filósofo Jörn Rüsen afirma que o saber histórico se constitui ao relacionar e investigar os sentidos da representação e da imaginação (RÜSEN, 2007). Woortman (1956) deixa claro, que os viajantes primeiro imaginaram os selvagens, construíram, projetaram, depois o encontraram. Para Rüsen (2007) é desse modo que acontece a dinâmica entre representação do passado, a ação do presente e a expectativa do futuro que estabelece o movimento de consciência histórica, mediante as manifestações, narrativas de uma história que conto, de uma explicação, ou seja, de algo que construo.

Nesse sentido, o olhar sobre o passado muda conforme a realidade do presente, já que em cada período histórico coexistem diferentes interpretações e perspectivas. Na

\footnotetext{
${ }^{1}$ Parecer CNE/CP 3/2004 que estabelece as Diretrizes Curriculares Nacionais para a Educação das Relações Étnico-Raciais e para o Ensino de História e Cultura Afro-Brasileira e Africana.

${ }^{2}$ Petronilha Beatriz Gonçalves e Silva em entrevista para Fundação Cultural Palmares, publicada em 11 de janeiro de 2012. Disponível em http://www.palmares.gov.br/?p=17211
} 
contemporaneidade, grande parte da sociedade brasileira apresenta dificuldade em mudar esse olhar e reconhecer que a imagem e a questão do "índio" são resultados de uma educação colonizada, imposta ao longo dos processos históricos. As formas de representações do indígena sempre estiveram ligadas ao atraso, como o entrave às ações colonizadoras do desenvolvimento e ao progresso.

Koselleck (2013:197) fazendo uso das palavras de Goethe (1960:93) esclarece que a História precisa ser reescrita de tempos em tempos, sem a obrigação de um acontecimento original descoberto, mas pelo fato de que aparecem novas concepções, e o cidadão de uma época pode ser levado a questionar e reavaliar os desdobramentos do processo histórico que passou ou que segue em curso, atribuindo ao seu ofício uma nova forma. Neste contexto, se encontra a necessidade em iniciarmos um trabalho intenso na desconstrução desse imaginário nacional possibilitando as narrativas escritas que vem surgindo dos indígenas e sobre os indígenas na atualidade.

Diante do assunto, Walsh (2013) propõe uma nova pedagogia, que proporcione uma forma diferente de perceber e compreender a realidade, são as pedagogias decoloniais que, segundo a autora, rompem com a colonialidade e tornam possíveis outras maneiras de pensar, saber, sentir e existir.

Grande parte dos livros didáticos retratam os índios ligados apenas ao passado colonial, e não oferecem novas abordagens. Uma das aberturas que permite outras narrativas a serem pensadas e escritas na história do Brasil é a Lei 11.645/2008, pois, mesmo que o processo de construção de significados sobre o outro ocorra em vários campos sociais e não somente na escola ou nas aulas de História, este é um ambiente considerável para tal procedimento, uma vez que, tratar da questão indígena nesses espaços, permite aos professores e alunos conhecerem os grupos étnicos existentes no Brasil e assim analisarem as imagens, as formas de olhar e os códigos que atuam nos imaginários coletivos da sociedade.

As salas de aula, os materiais e livros didáticos são lugares de diálogos que permitem expandir a questão indígena e compreender como socialmente têm sido reproduzidas as representações sobre esses povos, proporcionando outras aproximações com o conhecimento de suas histórias e culturas.

\section{O ensino da História e Cultura Indígena}

As salas de aula são espaços privilegiados, para a produção do conhecimento, pois nelas o processo de ensino e aprendizado acontece de forma sistematizada e constante, 
portanto, da transformação da consciência histórica. Rüsen (2007) traz contribuições referentes ao ensino, apresentando dentro da teoria da História, reflexões relacionadas à formação e ao saber histórico o qual consiste em analisar os elementos historiográficos e sua forma de representação. Isso implica na questão da função didática do historiador na instituição escolar, o modo como transmite o conhecimento aos alunos e o conteúdo por ele apresentado. O historiador exerce um papel fundamental na construção do conhecimento histórico crítico e formação da visão crítica da sociedade. Ao escolher um posicionamento dentro da historiografia está manifestando uma consciência histórica.

Nesse cenário, ao assumirmos as salas de aulas como espaços privilegiados aos debates sobre a questão indígena salienta-se, a importância das disciplinas em questão, os conteúdos tratados e a formação do educador e do público-alvo a qual se destina a narrativa oral e escrita.

Perceber nos livros didáticos o que é dito e o que é silenciado implica a articulação da vida prática dos professores e o modo como lidam com suas perspectivas e trajetórias em sala de aula. É relevante nos atentarmos aos conteúdos dos livros didáticos utilizados nas escolas públicas observando se existe a inclusão de conteúdos na visão histórico-cultural a partir dos povos indígenas e assim reconhecer que essas populações não são apenas vítimas da história e sim sujeitos dela. (Cunha 1992:24).

Nesse exercício de reflexão, partimos dos livros do Projeto Araribá - História, do $6^{\circ}$ ao $9^{\circ}$ ano do Ensino Fundamental. (Apolinário, 2014). Observamos como a questão indígena é referenciada e como o conteúdo é amparado por textos e imagens que enfatizam o período da colonização europeia no continente americano. No primeiro livro analisado do $6^{\circ}$ ano, na Unidade 3, a partir da página 60 aparece no tema 1- "A chegada do homem à América. Nas páginas a seguir até a 67 a temática indígena é citada, explicando de forma bem resumida a passagem pelo Estreito de Bering, enunciando as novas hipóteses sobre o povoamento da América. Também trata dos modos de vida dos antigos ameríndios, os povos nômades, caçadores e coletores, onde as explicações são voltadas sobre como viviam os primeiros grupos humanos e nada se apresenta das histórias indígenas contemporâneas.

As páginas do livro do $7^{\circ}$ ano seguem com textos sobre os povos pré-colombianos, maias, astecas e incas. Avançando pelo material, encontramos na página 170 a seção "Os primeiros contatos entre indígenas e portugueses”. Nesse espaço de duas páginas é exposto um mapa dos povos indígenas em 1.500.

$\mathrm{Na}$ análise do livro do $8^{\circ}$ ano, deparamos $\operatorname{logo}$ na unidade 1 , com o assunto das missões jesuíticas e a imagem de ilustração de Theodore de Bry, datada de 1562 (Figura 1), 
representando indígenas Tupinambás e guerreiros inimigos capturados em guerra bebendo cauim em ritual antropofágico. A representação do ritual reflete o imaginário europeu sobre a existência indígena, no qual alguns relatos descrevem a selvageria e a barbárie como traços predominantes, "quanto os que demonstram a docilidade, a ingenuidade e a fragilidade às doenças, caracterizando-os como povos da infância” (Portela, 2011:128).

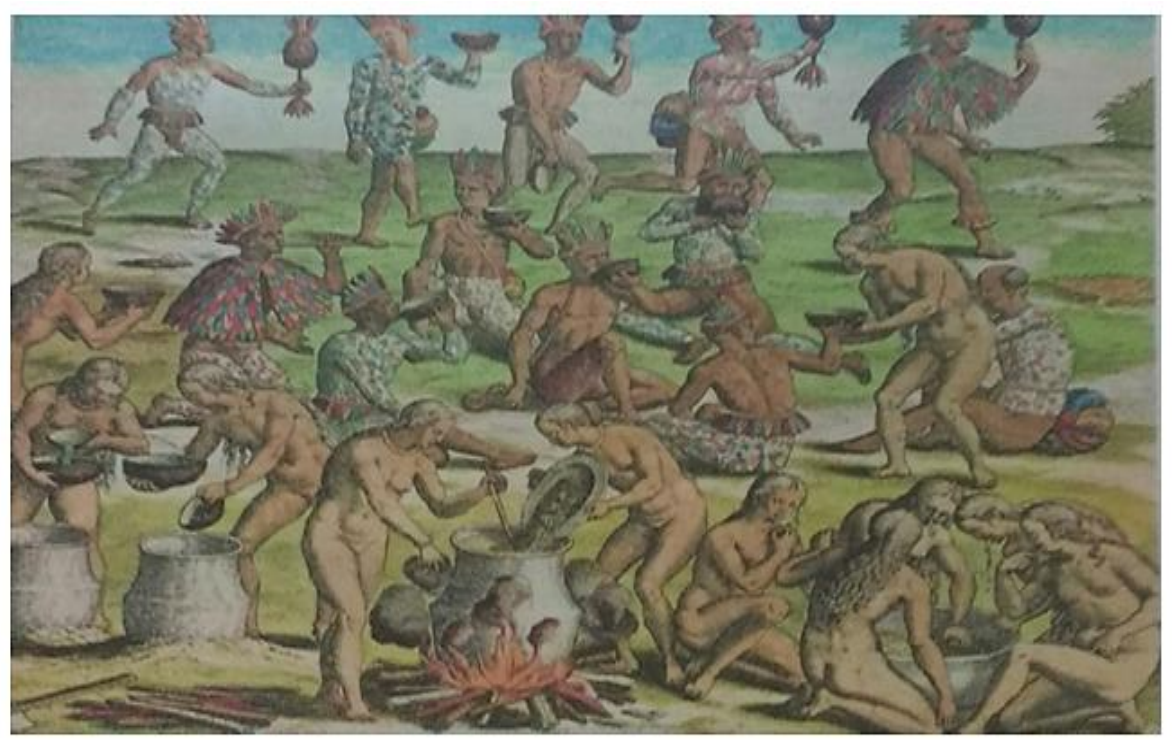

Figura 1: Representação de um ritual antropofágico.

Fonte: Apolinário (2014:22).

A maneira como as práticas dos povos indígenas é descrita e representada, incluindo os rituais antropofágicos amplamente divulgados por Hans Staden, são recebidos com horror e curiosidade, uma vez que o canibalismo, de certa forma, mostrou uma divergência nos métodos de indígenas e seus algozes invasores. $\mathrm{O}$ ato de ingerir pedaços da carne do capturado aparecia no imaginário europeu ora como forma de vingança dos inimigos vencidos, ora como ritual para adquirir as características das pessoas sacrificadas (Agnolin, 2002; Sallas, 2010).

No segundo livro do $7^{\circ}$ ano a partir da unidade 6, na página 132 encontramos exposto na abertura da página, o Artigo 8 da Declaração das Nações Unidas sobre os Direitos dos povos indígenas e um anúncio referente a tais direitos relatando sobre a invasão de seus territórios em diversos países da América Latina. Aparece a questão: "Como você vê a situação dos indígenas no Brasil atual?" Antes desse questionamento não é apresentado nenhum outro abordando a questão do esbulho em relação às terras indígenas no Brasil, ou as mortes recorrentes da luta pelo território. 
Esse imaginário ainda persiste em alguns campos da sociedade brasileira e a escola enquanto reflexo e produtora de mundos, também contribui para a construção de imaginários. Essa é uma indagação constante que atravessa muitos percursos reflexivos, pois diz respeito em relação à produção epistemológica cujos fundamentos interessam e são caros à prática docente pautada na decolonialidade.

Boaventura de Sousa Santos (2009) argumenta que a contemporaneidade carece de diferentes saberes, sendo os saberes indígenas fontes que muito podem ensinar. O sistema capitalista e seus mecanismos trouxeram problemas ecológicos, como: poluição, o crescente desmatamento, a exacerbação das desigualdades estruturais, entre outros contextos que nos permite pensar as convergências dos outros caminhos, para o processo de descolonização, no qual as sociedades indígenas constroem espaços que "vêm mostrando que sua resistência não está centrada na possibilidade delas absorverem ou não elementos da cultura dominante, mas sim na forma como esses elementos podem ser rearticulados positivamente por elas" (Chamorro, 2008:54).

Pensamos, portanto, a partir do contexto atual, como se tem produzido os discursos sobre os povos indígenas, a partir da instituição escolar e o lugar social dos indivíduos, e como se articula o conhecimento, as formas de imaginar os sujeitos, os saberes e poderes das inúmeras cartografias indígenas no Brasil, bem como destacar as especificidades e processos das culturas dos índios de cada estado e região.



Em outro caso, encontrado no livro didático direcionado a alunos do $9^{\circ}$ ano, na página 144, há uma imagem de Marechal Candido Rondon em visita a uma aldeia indígena (ver 
Figura 2 acima). A imagem repercutiu intensamente nas propagandas do governo Vargas. $\mathrm{O}$ texto relata que o Estado brasileiro continuava a tratar os índios como incapazes e que necessitavam de tutela. Além desse texto não foi encontrado nenhum outro que tratasse da Cultura e da História indígena em relação ao Brasil atual.

Eremites de Oliveira expõe que as narrativas indígenas que vem emergindo são trajetórias vivas, cuja expressão está na história de seu tempo presente (Eremites de Oliveira 2012:200). Com a formação dos professores indígenas nas universidades, as produções de materiais didáticos e acadêmicos tem aumentado. São produções que fortalecem a expressão das culturas, das ecologias, políticas, práticas socioculturais, formas de vida, rezas, cantos e outros elementos que marcam suas trajetórias.

Outro ponto que merece atenção é como as escritas dos próprios povos originários podem abrir caminhos para a construção e protagonismo de suas próprias histórias, possibilitando a desconstrução da imagem do indígena genérico, vitimado e fadado ao esquecimento. É relevante nos atentarmos aos conteúdos dos livros didáticos, utilizados nas escolas públicas e privadas, observando se existe a inclusão de conteúdos na visão históricocultural a partir dos povos indígenas, já que o processo de descolonização dos currículos envolve as lutas indígenas por um reconhecimento real de seus interesses e direitos. Tal urgência aparece na escrita de Daniel Munduruku (2012:16):

\footnotetext{
Enquanto isso - e longe da realidade fantasiosa imposta pela escola, pela literatura e pela mídia - os povos nativos continuam a ser massacrados pela ganância do desenvolvimento a todo custo e a ter seu modo de vida e sua visão de mundo sempre mais detonados pelo modelo econômico em que vivem. Invasões dos territórios, roubo de seus conhecimentos tradicionais, presença missionária alienante, perseguições políticas, roubo de suas riquezas materiais e imateriais, [...] são problemas enfrentados diuturnamente por comunidades embrenhadas por um Brasil desconhecido ou ocultado da maior parte da nação.
}

Em relação aos materiais didáticos, Rüsen (2007) aponta que para o ensino e aprendizagem da história, o livro didático é uma das ferramentas mais importantes, no qual muitos departamentos de cultura e educação tem interesse, pois contribuem na formação dos sujeitos na sociedade.

Aos historiadores, o que compete na escrita da História é articular suas fontes e recortes da documentação, localizar seus sujeitos e suas ações que produzem o lugar social no qual o indivíduo encontra-se inserido (Certeau, 1982). Portanto, a necessidade da construção e elaboração dos conteúdos dos livros didáticos deve abranger e expor a existência da diversidade cultural e étnica. 
A produção do conhecimento ligada às práticas sociais, e às ações políticas dos movimentos sociais, possibilitam a compreensão e a interpretação de nós mesmos e do mundo pela atividade da consciência, considerando como base existencial da consciência histórica, o processo da constituição da narrativa de sentido, na qual o saber histórico é inserido (mediante narrativa) nos processos comunicativos de vida humana prática, segundo Rüsen (2007).

Nessa perspectiva, orientar o saber histórico compete aos profissionais do contexto educacional, tendo a didática como ferramenta para a sala de aula, no ensinar, formular e refletir, uma vez que, "a percepção de uma política e de uma consciência histórica em que os índios são sujeitos e não apenas vítimas só é nova eventualmente para nós. Para os índios, ela parece ser costumeira" (Cunha, 1992:24).

O cumprimento da Lei 11.645/2008 deve ser o fio condutor para a efetivação de política educacional voltada para os povos indígenas, mostrando a necessidade de descolonizar o currículo, já que apresentam visões limitantes a respeito das culturas nativas, onde torna-se salutar questionar: $\mathrm{O}$ que realmente é debatido e problematizado em sala de aula? O que é apresentado na instituição escolar a respeito da questão indígena: o indígena como um ser vinculado eternamente ao passado, na composição do povo brasileiro ou o indígena como um sujeito genérico, sem atentar para a diversidade cultural das mais de trezentas etnias presentes em nosso país?

O Parecer CNE/CP3/2004, conforme já citado neste trabalho, se apresenta muito objetivo sobre a obrigatoriedade do ensino de História e Cultura Afro-brasileira e Africana. Nesse caminho, sua aplicação no cotidiano prático, dentro e fora da escola, não visa tornar ninguém mais erudito, mas nos provoca a pensar sobre uma reeducação sobre as relações étnico-raciais a fim de que todos, em suas maneiras diversas - descendentes de europeus, africanos, asiáticos e povos indígenas - valorizem as identidades, as culturas e as histórias de outros segmentos sociais, etnias, bem como suas especificidades, costumes, línguas e cosmologias, evitando criar uma imaginação única das existências, notadamente, no caso deste trabalho, as existências indígenas.

Entre os questionamentos levantados, ressaltamos que a mudança curricular é entendida como campo de disputas políticas e relações de poder. Perceber nos livros didáticos o que é dito e o que é silenciado implica a articulação da vida prática dos professores e o modo como lidam com suas perspectivas e trajetórias em sala de aula. 


\section{O diálogo e reconhecimento pluriétnico na perspectiva decolonial}

Ao chegarem à eterna primavera, paraíso descoberto, os navegantes, e primeiros viajantes, iniciam a história canônica do Brasil, dando a cada lugar o nome de um Santo, e assim, nomeando, tomando posse, é que o país foi simbolicamente criado (Cunha, 1992).

Sobre a realidade indígena no Brasil, sabe-se que com o pretexto de trazer a modernidade à América, os europeus, a partir do século XVI, colonizaram os povos originários, explorando todos os aspectos do país, e como não há modernidade sem a exploração de uma grande parte da humanidade, a colonialidade chegou de uma vez só, outorgando o direito de dizer o que era melhor para o outro, sem que houvesse qualquer diálogo. A maior cilada foi a ilusão de primitivismo, de sociedades fixadas ao atraso, ligadas a uma eterna infância. "E, porque tinham assim parado no tempo, não cabiam procurar-lhes a história." (Cunha, 1992:11). A partir do século XVII, pelo menos, a ideia de modernidade se apresenta como prelúdio da revolução redentora de novos princípios civilizatórios, cujo cerne tenta invocar uma reordenação do conhecimento, a partir de um método baseado numa razão antropológica que reorganiza a própria condição do estabelecimento daquilo que conhecemos como sociedade (Da Silva, 2003:154).

Para tanto, a modernização tem como objetivo, às vezes diluído e disfarçado como benevolência, a homogeneização, a assimilação e a simplificação das trajetórias indígenas no processo de globalização, promovendo um choque entre as culturas locais e globais. O mundo social vive um duelo entre o antigo e o novo, onde o passado e o presente continuam em uma ocasião de mudança e renovação. As concepções etnocêntricas de modernidade inserem as diferenças enquanto fatores de inferioridade e desigualdade, a partir de modelos padronizados de humanidade.

O conhecimento materializado nos currículos tem sido predominantemente eurocêntrico, como uma forma de exercício de poder que inferioriza o outro, evidenciando identidades através da criação violenta de alteridades que exigem a subordinação, violação e opressão. Diante dessas ideias eurocêntricas, a Lei 11.645/2008, pode servir para descolonizar o currículo na superação dos conceitos coloniais exigindo entender que o descolonizar é uma práxis baseada na insurgência educativa propositiva e não apenas denunciativa, cuja finalidade é construir outras opções pedagógicas, além das já existentes.

Ao inserir nos currículos educacionais, conteúdos referentes à temática indígena a intenção é construir uma pedagogia decolonial na medida em que questiona os referenciais eurocêntricos a partir dos quais o conhecimento no campo das ciências sociais é produzido. 
Nas escolas, a Lei 11.645/2008 simboliza uma grande conquista, resultado das lutas dos povos originários, cujo objetivo sempre fora ter o reconhecimento pluriétnico do país, dando condições para que os mais variados profissionais da educação discutam a realidade de silêncio e opressão vividos por tais povos.

O maior desafio de uma dinâmica decolonial envolvendo a Lei 11.645/2008 é a superação ideológica da matriz colonial europeia e a construção de materiais didáticos que apresente de maneira substancial a história indígena contemporânea, e com isso haja a promoção da "visibilidade dos atores indígenas, contribuindo para desconstruir as imagens depreciativas ou negativas dos grupos étnicos, que continuam existindo na sociedade global” (Chamorro, 2015:20). Prontamente, cabe aos profissionais e responsáveis pela educação compreender que o trabalho com a temática indígena nas escolas implica a necessidade de incorporar outras cosmovisões no tratamento de conteúdo, bem como a inserção de políticas educativas que objetivem estabelecer uma nova visão histórico-cultural.

Diante das transgressões e violação do ser indígena como sujeito histórico, a cultura apresenta formas e características diferentes no espaço e no tempo. Vide as produções de Ailton Krenak (2020), Daniel Munduruku (2001), Eliane Potiguara (2004) e outras vozes. Os povos indígenas buscam o reconhecimento coletivo de suas tradições que consiste como algo vivo, autônomo e contínuo e não de forma estagnada.

Em resposta a essa colonialidade, surge no século $\mathrm{XX}$, a decolonialidade epistemológica, sendo assim, relatado por Santos (2009) e Bertagnolli (2015) como Epistemologia do Sul, cuja finalidade é a recuperação dos saberes e práticas dos grupos sociais que, devido ao capitalismo e ações coloniais, foram colocados no arranjo apenas de objetos ou matéria-prima dos saberes dominantes.

O pensamento decolonial é relevante para o campo dos estudos culturais na medida que apresenta métodos e metodologias que não reforçam as violências culturais e históricas associadas às tradições eurocêntricas. A tarefa decolonial é movimentar o que é a representação, e de quais formas e em quais contextos ocorre uma distinção filosófica entre o $\mathrm{Eu}$ e o Outro, conhecedor e conhecido, lutando dentro do contrassenso da igualdade, da particularidade e da universalidade exigindo um novo pensar epistêmico.

\section{Considerações Finais}

O ensaio possibilita compreender algumas dimensões da construção do imaginário social colonialista, notadamente expressada através de elementos textuais e imagéticos que 
são pertinentes à elaboração do conhecimento histórico e da consciência histórica, reconhecendo os dilemas contemporâneos pautados na questão do ensino da História e Cultura Indígena em instituições educacionais, permeando o objeto de pesquisa dentro da perspectiva decolonial.

De fato, o historiador exerce o ofício de construir o conhecimento, de produzir, ensinar e divulgar os fenômenos e processos históricos, contribuindo para a produção do saber, de modo que a pesquisa, a escrita e a educação histórica façam sentido aos destinatários. A forma de pesquisa e de escrita da história vem sendo revista "[...] desde do início da escola dos Annales, porém a História que continua sendo escrita e ensinada na maioria dos livros didáticos está centrada na Europa, no ocidente e em homens brancos” (Brocardo; Tecchio, 2017:2). Entretanto, o cenário atual brasileiro exige de nós novas formas de pensar e de agir.

Percebe-se o quanto é relevante caminhar no sentido de uma história indígena que não seja temporalmente determinada pela narrativa colonial. Cabe aos estudos decoloniais promover novas abordagens que contemplem outros sujeitos e assim multiplique as noções usuais do pensamento histórico, construído por uma voz única, reprodutor de discursos universalizantes da problemática noção de "índio eterno", percebendo por meio dos livros didáticos o que é dito, e o que é silenciado nas narrativas sobre os povos nativos.

Juntamente com as leis e o direito à terra, está a questão primordial que é compreendermos como os povos originários tem sido representados e permanecem no imaginário da sociedade nacional, bem como nos espaços educacionais. Para que a Lei 11.645/2008 tenha êxito, é fundamental que seja superada a perspectiva eurocêntrica para que a relação dos conteúdos e trajetórias dos povos nativos seja trabalhada como processo histórico contínuo, autônomo e aberto.

\section{Referências}

AGNOLIN, Adone (2002), “Antropofagia ritual e identidade cultural entre os Tupinambá". Revista de Antropologia, v. 45, n. 1, pp. 131-185 [Consul. 05-06-2020]. Disponível em https://doi.org/10.1590/S0034-77012002000100005

APOLINÁRIO, Raquel Maria (2014), Projeto Araribá História. 4. Ed. São Paulo, Editora Moderna.

BRASIL (2008), Lei n. ${ }^{\circ} 11.645$, de 10 março de 2008. Diário Oficial da República Federativa do Brasil. Brasília, Poder Executivo.

BERTAGNOLLI Gissele Leal (2015), "Da Colonialidade à Descolonialidade: diálogos de ciências a partir de uma 'Epistemologia do Sul' - Uma análise de comunidades Quilombolas". Revista Grifos, v. 24, n. 38/39, pp. 231-241 [Consult 15-06-2020]. Disponível em https://doi.org/10.22295/grifos.v24i38/39.3283 
BLOCH, Marc (2001), Apologia da história ou O ofício do historiador. Rio de Janeiro, Jorge Zahar.

BROCARDO, Daniele. TECCHIO, Caroline (2017), Olhares para a História: pós-colonialismo, estudos subalternos e decolonialidade. Revista Latino-Americana de Estudos em Cultura e Sociedade, v. 3 [Consul. 05-05-2020]. Disponível em https://doi.org/10.23899/relacult.v3i3.496

CERTEAU, Michel (1982), A escrita da História. Rio de Janeiro, Forense-Universitária.

CUNHA, Manuela Carneiro da (1992), Introdução a uma história indígena. São Paulo, Companhia das Letras.

CHAMORRO, G. (2008), Terra madura, yvy araguyje: fundamento da palavra guarani. Dourados, Editora da UFGD.

CHAMORRO, Graciela; COMBES, Isabelle (2015), Povos Indígenas em Mato Grosso do Sul: história, cultura e transformações sociais. 1. ed. Dourado, UFGD.

CHARTIER, Roger (2009), A história ou a leitura do tempo, tradução de Cristina Antunes. Belo Horizonte, Autêntica Editora.

DA SILVA, Mozart Linhares (2003), "Educação intercultural e pós-modernidade". Revista Subjetividades, v. 3, n. 1, pp. 151-163 [Consult. 10-11-2020]. Disponível em http://pepsic.bvsalud.org/pdf/malestar/v3n1/09.pdf

EREMITES DE OLIVEIRA, Jorge (2012), “A história indígena no Brasil e em Mato Grosso do Sul”, Espaço ameríndio, v. 6, n. 2, pp. 178.

FANELLI, Giovana de Cássia Ramos (2018), A Lei 11.645/08: história e mudança curricular. Guarulhos, UNIFESP.

KRENAK, Ailton (2020), O amanhã não está à venda. Rio de Janeiro, Companhia das Letras.

KOSELLECK. Reinhart (2013), O conceito de História. Belo Horizonte, Autêntica Editora.

MIGNOLO, Walter (2005), A colonialidade de cabo a rabo: o hemisfério ocidental no horizonte conceitual da modernidade. Buenos Aires, Clacso, pp. 35-54 [Consult. 20-12-2020]. Disponível em http://biblioteca.clacso.edu.ar/clacso/sur-sur/20100624094657/6_Mignolo.pdf

MUNDURUKU, Daniel (2001), As serpentes que roubaram a noite: e outros mitos. São Paulo, Editora Peirópolis.

MUNDURUKU, Daniel (2012), "Literatura indígena e as novas tecnologias da memória". Revista LEETRA Indígena, v. 1, n. 1, pp. 16-23 [Consult. 15-05-2020]. Disponível em https://issuu.com/grupo.leetra/docs/leetra_vol1

PORTElA, Cristiane de Assis (2011), Para além do "Caráter ou qualidade de indígena": uma história do conceito de indigenismo no Brasil. Tese (Doutorado em História). Universidade de Brasília- UNB.

POTIGUARA, Eliane (2004), Metade cara, metade máscara. São Paulo, Global Editora.

RÜSEN, Jörn (2007), História Viva: teoria da história: formas e funções do conhecimento histórico. Brasília, Editora. Universidade de Brasília, 160 p. 
SALLAS, Ana Luisa Fayet (2010), "Narrativas e imagens dos viajantes alemães no Brasil do século XIX: a construção do imaginário sobre os povos indígenas, a história e a nação". História, Ciências, Saúde - Manguinhos, v. 17, n. 2, pp. 415-435 [Consul 15-05-2020]. Disponível em https://doi.org/10.1590/S0104-59702010000200009

SANTOS, Boaventura de Sousa; MENESES, M. P. (Orgs.) (2009), Epistemologias do Sul. Coimbra, Almedina.

TODOROV, Tzvetan (2003), La conquista de América: el problema del otro. Buenos Aires, Siglo veintiuno editores Argentina.

WALSH, Catherine (2013), Pedagogías decoloniales: prácticas insurgentes de resistir, (re)existir y (re)vivir. Tomo I. Quito, Ecuador, Ediciones Abya-Yala.

WOORTMANN, Klaas (2004), O selvagem e o Novo Mundo: ameríndios, humanismo e escatologia. Brasília, Editora Universal de Brasília. 


\begin{abstract}
The purpose of the essay is to reflect on the social imaginery in Brazilian society about indigenous populations. To investigate how this imaginary is represented in the school context and in the teaching materials, observing Law 11,645 / 2008, promulgated in order to correspond to the desires and requirements of the hundreds of indigenous ethnic groups in Brazil. The analysis seeks, through theoretical research, to think from the decolonial theory, the need to report the indigenous histories and cultures in the curriculum of the educational context. In this direction, the present essay proposes to evaluate the influence of textbooks on the development of the historical awareness of students and the surrounding society.
\end{abstract}

Keywords: Law 11.645/2008; decolonial theory; indigenous issue; historical consciousness.

\title{
Resumen
}

El propósito del ensayo es reflexionar sobre la imaginación social brasileña sobre las poblaciones indígenas. Para investigar cómo se representa este imaginario en el contexto escolar y en los materiales de enseñanza, observando la Ley 11.645 / 2008, promulgada para cumplir con los deseos y requisitos de los cientos de grupos étnicos indígenas en Brasil. El análisis busca, a través de la investigación teórica, pensar desde la teoría decolonial, la necesidad de relacionar las historias y culturas indígenas en los planes de estudio del contexto educativo. En esta dirección, este ensayo propone evaluar la influencia de los libros de texto en el desarrollo de la conciencia histórica de los estudiantes y la sociedad circundante.

Palabras clave: Ley 11.645/2008; teoría decolonial; problema indígena; conciencia histórica. 